\title{
Can early hyperglycemia affect the morbidity/mortality of very low birth weight premature infants?
}

\author{
Aleksandra Simovic ${ }^{1 \oplus}$, Admir Kuc ${ }^{1 \oplus}$, Ema Jevtic ${ }^{1 \oplus}$, Aleksandar Kocovic ${ }^{2 \oplus}$, \\ Slavica Markovic ${ }^{1 \oplus}$, Marina Stanojevic ${ }^{1 \oplus}$, Maja Jakovcevski ${ }^{3 \oplus}$, Dejan Jeremic ${ }^{3 \odot}$ \\ Departments of ${ }^{1}$ Pediatrics, ${ }^{2}$ Pharmacy and ${ }^{3}$ Anatomy, University of Kragujevac, Faculty of Medical Sciences, Serbia.
}

\begin{abstract}
Background. The study aimed to examine the effect of early hyperglycemia on the morbidity/mortality of very low birth weight premature infants.

Methods. This retrospective study included all premature infants with gestational age $\leq 32$ gestational weeks, hospitalized at the Department of Intensive Neonatal Care, Clinical Center Kragujevac, during the period 2017-2019. Hyperglycemia was defined as glycemia of $\geq 12 \mathrm{mmol} / \mathrm{l}$ in one measurement, or $>10 \mathrm{mmol} / \mathrm{l}$ in two measurements, at repeated intervals of 2-4 hours. Glycemia was determined from capillary blood, using a gas analyzer of Gem Premier 3000, during the first 7 days of life. Continuous intravenous insulin infusion was administered after ineffective glucose restriction at glycemic values of $>14 \mathrm{mmol} / \mathrm{l}$.
\end{abstract}

Results. Patients with normoglycemia (41/72 (56.94\%)) and hyperglycemia (31/72 (43.06\%)) did not differ in gender, gestational age, mode of delivery and antenatal administration of steroids, while birth weight had a tendency to be lower in the hyperglycemic group $(p=0.052)$. Hyperglycemia was significantly associated with a low APGAR score at the fifth minute $(p=0.048)$, necrotizing enterocolitis $(p=0.011)$, and shorter duration of mechanical ventilation $(p=0.006)$. Hyperglycemia was associated with significantly more frequent fatal outcomes (35.5\%) when compared with the normoglycemic group (4.9\%). Accordingly, these patients required inotropic $(\mathrm{r}=0.036)$ and insulin therapy $(\mathrm{r}<0.001)$ more often. Retinopathy of prematurity, bronchopulmonary dysplasia and sepsis did not correlate with hyperglycemia in our study. Intraventricular hemorrhage of the first degree was more often associated with normoglycemia in premature infants on prolonged mechanical ventilation while more severe intracranial hemorrhage was more common in the hyperglycemic group but did not result in statistical significance due to the small number of patients.

Conclusions. Monitoring glucose levels in the blood of very low birth weight premature infants is clinically important because abnormalities in glucose homeostasis can have serious short-term and long-term consequences.

Key words: hyperglycemia, newborn, insulin, prognosis.

Hyperglycemia in the newborn is defined as a blood sugar value of $>7 \mathrm{mmol} / \mathrm{l}$, or $>8,3 \mathrm{mmol} / 1$ in premature babies and is a common problem in extremely immature babies. ${ }^{1-3}$ While it is widely known that non-treated hyperglycemia leads to irreversible damage of the central nervous system, there is still a lack of knowledge

$\triangle$ Marina Stanojevic

marinastanojevic87@yahoo.com

Received 29th May 2020, revised 23rd August 2020, accepted 26th November 2020. about the short-term and long-term effects of hyperglycemia on the development of preterm infants. $^{3-5}$ The prevalence of hyperglycemia in preterm infants is variable $(20-88 \%){ }^{2}$ These numbers probably underestimate the actual prevalence, as approximately $50 \%$ of hyperglycemias are not being detected using standard sampling methods and different data on hyperglycemia in preterm infants are found in the literature. ${ }^{1,2}$ There are many causes of hyperglycemia in neonates. The most common ones include excessive glucose intake, some 
drugs (corticosteroids, diazoxide, phenytoin, theophylline), defective glucose metabolism and hyperosmolar milk formulas. ${ }^{6}$ The main objective of this study was to examine the effect of early hyperglycemia on the morbidity/ mortality of very low birth weight (VLBW) premature infants.

\section{Material and Methods}

Data were prospectively collected from the Department of the Intensive Neonatal Care, Clinical Center Kragujevac during the 20172019 period. The analysis included all preterm children with a gestational age of $\leq 32$ weeks.

Exclusion criteria were the following: Weight at birth of $<400$ gram, gestational age of $>32$ weeks, the presence of congenital malformations, chromosome aberrations, genetic metabolic diseases, moving to another hospital for further treatment and death within the first $24 \mathrm{~h}$ of life.

Hyperglycemia was defined as a glucose level of $\geq 12 \mathrm{mmol} / \mathrm{l}$ in one measurement, or $\geq 10 \mathrm{mmol} / 1$ in two consecutive measurements, within the 2-4 h interval. ${ }^{6}$ Glucose levels were measured from capillary blood, using a gas analyzer Gem Premier 3000. Continual intravenous insulin was used after the glucose restriction failed to lower glycemia, at blood sugar values of $>14 \mathrm{mmol} / 1$. Data have been collected from the medical documentation, including routine diagnostic and therapeutic procedures conducted at the Department. All the information collected was coded in order to respect the right of anonymity of each respondent. Personal data was only available to authors for the purpose of obtaining the necessary results for scientific purposes. Ethical approval was obtained by the Faculty of Medical Science, University of Kragujevac on the scientific teaching council (number of decision IV-03-93/14 date 19.02.2020).

\section{Statistical analysis}

The study data were analyzed with descriptive statistics methods and presented in tables. Mean or median was used as a measure of central tendency and standard deviation or interquartile range as a measure of dispersion for continuous variables. Categorical variables were presented as rates or percentages. After checking the normality of the data distribution for the continuous variables (KolmogorovSmirnov test), appropriate parametric or nonparametric tests were applied (Student's T-test for independent samples or MannWhitney $\mathrm{U}$ test). The significance of differences in the rates of categorical variables' values was tested by the Chi-square test. The null hypothesis was considered to be not true if the probability of difference was less than 0.05 . The influence of hyperglycemia on the occurrence of diseases or death was evaluated by univariate and multivariate binary logistic regression analysis. The results were shown as crude and adjusted odds ratios (ORs) with corresponding 95\% confidence intervals (CI). All calculations were performed by statistical program for social sciences (SPSS version 18).

\section{Results}

Of the total number of preterm infants $26 / 72$ (36.11\%) developed hyperglycemia $>10 \mathrm{mmol} / 1$ and $24 / 72(33.33 \%)$ had glycemia $>12 \mathrm{mmol} / 1$. Hypoglycaemia $(<1.7 \mathrm{mmol} / \mathrm{l})$ developed in $4 / 72(5.56 \%)$ preterm neonates. Of the babies with a birth weight $<1500 \mathrm{~g} 21 / 72$ (29.17\%) had normoglycemia. Infants with normal (41/72 $(56.94 \%))$ and elevated (31/72 (43.06\%)) glucose levels did not differ in sex, gestational age, route of delivery, antenatal use of steroids, while the body weight at birth had a tendency to be lower in the hyperglycemic group but this did not reach statistical significance $(p=0.052$; Table I). The median of average blood glucose level during hospitalization in the hyperglycemic group was $11.8(9.7-14.8) \mathrm{mmol} / \mathrm{l}$, so these infants significantly more often required insulin $(p<0.001)$ or inotropic $(p=0.036)$ therapy, compared with normoglycemic infants (Table II). Four babies $(4 / 21(19.05 \%))$ with normal glucose levels later developed hypoglycemia. Hyperglycemia correlated significantly with low APGAR score at the 5th minute 
Table I. Baseline characteristics of newborns.

\begin{tabular}{|c|c|c|c|}
\hline Variable & $\begin{array}{l}\text { Cases } \\
\mathrm{n}=31 \\
\mathrm{M}(\mathrm{IQR})\end{array}$ & $\begin{array}{l}\text { Controls } \\
\mathrm{n}=41 \\
\mathrm{M}(\mathrm{IQR})\end{array}$ & $\begin{array}{l}\text { Test value and } \\
\text { significance of null } \\
\text { hypothesis }\end{array}$ \\
\hline Gestational age (weeks) & $29(26-32)$ & $30(29-32)$ & $\begin{array}{l}U=501.500 \\
p=0.122\end{array}$ \\
\hline Weight at birth (g) & $1180(810-1930)$ & $1450(1235-1895)$ & $\begin{array}{l}U=464.500 \\
p=0.052\end{array}$ \\
\hline APGAR score in fifth minute & $5(3-8)$ & $7(6-8)$ & $\begin{array}{l}U=464.000 \\
p=0.048^{*}\end{array}$ \\
\hline Mechanical ventilation (days) & $6(4-11)$ & $11(7.5-24)$ & $\begin{array}{l}U=395.000 \\
p=0.006^{*}\end{array}$ \\
\hline
\end{tabular}

p- statistical significance; * - statistically significant; M: median, IQR: interquartile range

Table II. Values of glucose and inflammation biomarkers.

\begin{tabular}{llll}
\hline \multirow{2}{*}{ Variable } & Cases & Controls & Test value and \\
& $\mathrm{n}=31$ & $\mathrm{n}=41$ & $\begin{array}{l}\text { significance of null } \\
\text { hypothesis }\end{array}$ \\
& $\mathrm{M}(\mathrm{IQR})$ & $\mathrm{M}(\mathrm{IQR})$ & $\mathrm{U}=19.000$ \\
Average glucose $(\mathrm{mmol} / \mathrm{l})$ & 11.8 & 4.7 & $\mathrm{p}<0.001^{*}$ \\
Average CRP $(\mathrm{mg} / \mathrm{l})$ & $(9.7-14.8)$ & $(4.2-6.0)$ & $\mathrm{U}=388.500$ \\
& 8.3 & 3.5 & $\mathrm{p}=0.005^{*}$ \\
Average PCT $(\mathrm{ng} / \mathrm{ml})$ & $(3.2-16.7)$ & $(1.4-6.2)$ & $\mathrm{U}=632.500$ \\
& 4.68 & 4.61 & $\mathrm{p}=0.973$
\end{tabular}

p- statistical significance; * - statistically significant; M: median, IQR: interquartile range, CRP: C reactive protein, PCT: procalcitonin

$(p=0.048)$ and a shorter duration of mechanical ventilation $(p=0.006)$ (Table I). Congruently, necrotizing enterocolitis (NEC), intraventricular hemorrhage (IVH) of the second and thirddegree, and lethal outcomes were more frequent in hyperglycemic subjects. Normoglycemia was more frequently correlated with premature retinopathy (ROP) at site $2 \mathrm{~B}$, as well as IVH of the first degree (Table III) and significantly longer duration of mechanical ventilation (Table I). Table III also shows 13 deaths in the total group (two in the normoglycemic group). Seven $(7 / 13(53.8 \%))$ among the 13 received intravenous insulin. Three infants with normoglycemia $(3 / 21,(14.29 \%))$ who later developed hyperglycemia were also treated with continuous intravenous insulin. The number of positive blood cultures taken during admission to the neonatal intensive care unit, as well as the values of inflammatory markers did not differ significantly in the observed groups.

The results of both univariate and multivariate binary logistic regression analysis of hyperglycemia association with investigated diseases or lethal outcome, with adjustment for potential confounders are shown in Table IV. Variables entered for multivariate analysis were: gender, gestational age, weight at birth, APGAR score in the fifth minute and mode of delivery, diseases NEC, bronchopulmonary dysplasia (BPD), ROP and IVH, and also lethal outcome. Statistically significant association with hyperglycemia was found for the following variables: NEC, IVH Grade 1, ROP at site 2B, and lethal outcome (death). After adjusting for confounding variables association 
Table III. Clinical characteristics for cases and controls.

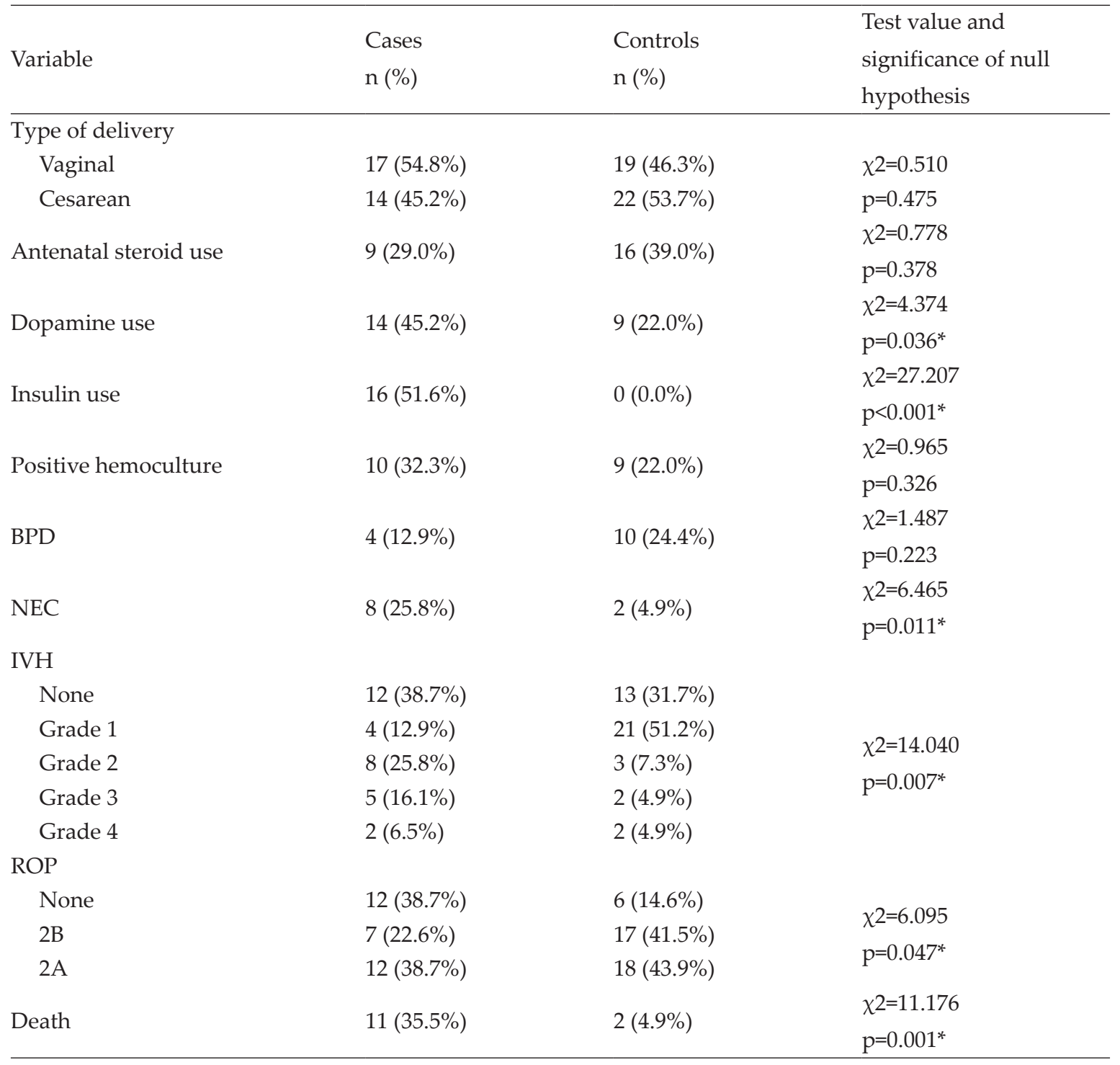

p- statistical significance; ${ }^{*}$ - statistically significant; M: median, IQR: interquartile range, BPD: bronchopulmonary dysplasia, NEC: necrotic enterocolitis, IVH: intraventricular hemorrhage, ROP: retinopathy of prematurity

of hyperglycemia and $\mathrm{ROP}$ at site $2 \mathrm{~B}$ lost its significance. ROP, BPD and sepsis did not correlate with hyperglycemia in our study.

\section{Discussion}

The results of our study show that preterm infants with hyperglycemia have lower APGAR scores in the fifth minute and spend less time on mechanical ventilation because the number of days of mechanical ventilation was equal to the number of days until death in $1 / 3$ of cases. The risk of hyperglycemia is inversely related to gestational age and birth weight and increases with the presence of comorbidities ${ }^{1,2,6}$, similar to our results.

There is a higher risk for premature infants with VLBW and hyperglycemia to develop NEC and IVH grade $\geq 2$, and eventually, die. These patients have significantly higher values of minimum, average, and maximum blood glucose levels and are more likely to require dopamine or insulin 
Table IV. Logistic regression analysis of hyperglycemia as a risk factor for the occurrence of diseases or death.

\begin{tabular}{|c|c|c|}
\hline & Crude OR & Adjusted\# OR \\
\hline \multirow[t]{2}{*}{ Disease/Death } & $(95 \%$ CI) & $(95 \%$ CI) \\
\hline & $\mathrm{p}$ & $\mathrm{p}$ \\
\hline & 0.459 & 0.332 \\
\hline \multirow[t]{3}{*}{ BPD } & $(0.129-1.634)$ & $(0.084-1.317)$ \\
\hline & $\mathrm{p}=0.229$ & $\mathrm{p}=0.117$ \\
\hline & 6.783 & 6.163 \\
\hline \multirow[t]{2}{*}{ NEC } & $(1.325-34.719)$ & $(1.043-36.427)$ \\
\hline & $\mathrm{p}=0.022^{*}$ & $\mathrm{p}=0.045^{*}$ \\
\hline \multicolumn{3}{|l|}{ IVH } \\
\hline \multirow{4}{*}{ Grade 1} & 0.206 & 0.166 \\
\hline & $(0.055-0.777)$ & $(0.040-0.694)$ \\
\hline & $\mathrm{p}=0.020^{*}$ & $\mathrm{p}=0.014^{*}$ \\
\hline & 2.889 & 3.282 \\
\hline \multirow[t]{3}{*}{ Grade 2} & $(0.618-13.496)$ & $(0.566-19.023)$ \\
\hline & $\mathrm{p}=0.177$ & $\mathrm{p}=0.185$ \\
\hline & 2.708 & 1.916 \\
\hline \multirow[t]{3}{*}{ Grade 3} & $(0.440-16.680)$ & $(0.232-15.859)$ \\
\hline & $\mathrm{p}=0.283$ & $\mathrm{p}=0.546$ \\
\hline & 1.083 & 0.836 \\
\hline \multirow[t]{2}{*}{ Grade 4} & $(0.131-8.946)$ & $(0.079-8.888)$ \\
\hline & $\mathrm{p}=0.941$ & $\mathrm{p}=0.882$ \\
\hline \multicolumn{3}{|l|}{ ROP } \\
\hline \multirow{4}{*}{$2 B$} & 0.206 & 0.257 \\
\hline & $(0.055-0.769)$ & $(0.055-1.200)$ \\
\hline & $\mathrm{p}=0.019^{*}$ & $\mathrm{p}=0.084$ \\
\hline & 0.333 & 0.347 \\
\hline \multirow[t]{3}{*}{$2 \mathrm{~A}$} & $(0.098-1.132)$ & $(0.095-1.267)$ \\
\hline & $\mathrm{p}=0.078$ & $\mathrm{p}=0.109$ \\
\hline & 10.725 & 7.576 \\
\hline \multirow[t]{2}{*}{ Death } & (2.165-53.130) & (1.105-51.936) \\
\hline & $\mathrm{p}=0.004^{*}$ & $\mathrm{p}=0.039^{*}$ \\
\hline
\end{tabular}

p- statistical significance; ${ }^{*}$ - statistically significant; BPD: bronchopulmonary dysplasia, NEC: necrotic enterocolitis, IVH: intraventricular hemorrhage, ROP: retinopathy of prematurity

\#- Adjusted for gender, gestational age, weight at birth, APGAR score in fifth minute and type of delivery

therapy. A study conducted in Iran in 2014 showed that hyperglycemia in preterm infants correlates with perinatal asphyxia, respiratory distress syndrome, and inotropic use, which is comparable to our results. ${ }^{6}$ The reasons for the predisposition to hyperglycemia in VLBW infants are numerous and include all factors that interfere with insulin synthesis/secretion and/or cause insulin resistance. Both cases and controls in our study were of VLBW which did not differ significantly between these groups. This allows us to estimate the influence of other investigated factors adequately. First of all, the immature pancreas fails to synthesize enough proinsulin, with premature infants secreting proinsulin peptides that are recognized as "insulin" by standard tests but have only limited biological activity. It is generally accepted that preterm 
infants have a limited ability to secrete insulin, which promotes hepatic glucose synthesis and activates gluconeogenesis. Immature liver in newborns has reduced sensitivity to insulin, so it continues to release glucose despite hyperglycemia. On the other hand, neonates with VLBW have increased insulin resistance in peripheral tissues due to poorer function of the immature insulin-receptor complex which is worsened during clinical stress. $^{7}$ Additional suppression of insulin secretion in preterm infants with temporary or permanent hypoxia is exacerbated by increased catecholamine tone (mainly norepinephrine), while other forms of clinical stress increase hepatic glucose synthesis through increased secretion of cortisol, glucagon, and growth hormone. ${ }^{1,6}$ Treatment with catecholamines, corticosteroids, and some other drugs can also contribute to hyperglycemia. In studies in which corticosteroids (dexamethasone) were used postnatally to prevent chronic lung disease, the risk of hyperglycemia and glycosuria was increased. Furthermore, the absence, late-onset, or slow intake of parenteral nutrition limits the production of gastrointestinal incretins and their positive effects on insulin secretion. ${ }^{8}$ Likewise, high-dose intravenous lipids directly reduce glucose oxidation, provide glycerol as a "fuel" for gluconeogenesis, and contribute to the formation of $\beta$-oxidation products in the liver that activates gluconeogenesis coenzymes, all contributing to hyperglycemia. ${ }^{6}$ Similar to our results, previous publications state that hyperglycemia was a risk factor for NEC and sepsis, which can cause prolonged hospitalization. ${ }^{1,6,9-11}$ Hyperglycemia usually occurs 2-3 days before the onset of clinical signs of infection and/or sepsis, more often in fungal than bacterial infections. ${ }^{9}$ Contrary to our results, neonatal hyperglycemia may be correlated with an increased risk for retinopathy and BPD. ${ }^{12-15}$ Our results showed that IVH grade 1 and ROP at site $2 \mathrm{~B}$ were reported significantly more often in the group with normoglycemia ( $p=0.020$ and $p=0.019$ respectively). The explanation may be a significantly longer duration of mechanical ventilation in these patients. ${ }^{16,17}$
However, the blood glucose threshold leading to such complications has not been established. ${ }^{17,18}$ Most neonatologists would intervene at blood sugar values of $10.0-11.1 \mathrm{mmol} / 1^{6,18}$ Some studies $^{3,6,19-20}$ similar to our results, showed that more severe complications occur after prolonged hyperglycemia and it is often in correlation with the increased mortality rate. A study conducted in Jerusalem in 2013 showed that in patients with IVH diagnosed within the first 96 hours, prolonged hyperglycemia exacerbated existing intraventricular hemorrhage. ${ }^{16}$ Thus, the duration of hyperglycemia is an important risk factor for the complex pathology of hyperglycemia. ${ }^{21}$ During neonatal infections, high levels of inflammatory markers, cytokines, and catecholamines promote the development of insulin resistance, while glucose production in the liver, the central organ of glucose homeostasis, is not inhibited. Although the pancreas should produce more insulin to make up for this, relative beta deficiency develops due to the immaturity of the beta cells. ${ }^{6}$

Although continuous insulin infusion has been used for 25 years to treat clinically relevant neonatal hyperglycemia, in many institutions the first step in its treatment is limited glucose uptake. ${ }^{19,22-24}$ A comparison between the two interventions proved the effectiveness of continuous insulin infusion in controlling glucose levels. Insulin-treated children had higher glucose intake, higher body weight, lower incidence of sepsis, and increased endogenous insulin secretion. ${ }^{23}$ The advantage of early insulin therapy in the prevention and treatment of hyperglycemia has been demonstrated in critically ill adults, but remains questionable in preterm infants, especially those born highly immature because it increases mortality from hypoglycemia in the first 28 days of life., ${ }^{64-26}$

Measurements of blood glucose levels are clinically important, as the high blood glucose levels increase the risk for developing necrotizing enterocolitis and severe grades of intraventricular hemorrhages which lead to prolonged hospitalization or early mortality in VLBW premature children. 


\section{Author contribution}

The authors confirm contribution to the paper as follows: study conception and design: Aleksandra Simovic; data collection: Admir Kuc, Ema Jevtic; analysis and interpretation of results: Aleksandar Kocovic, Slavica Markovic, Marina Stanojevic; draft manuscript preparation: Maja Jakovcevski, Dejan Jeremic. All authors reviewed the results and approved the final version of the manuscript.

\section{Ethical approval}

Ethical approval was obtained by the Faculty of Medical Science, University of Kragujevac on the scientific teaching council (number of decision IV-03-93/14 date 19.02.2020.).

\section{Source of funding}

We don't have any sources of financial assistance for this research.

\section{Conflict of interest}

All authors read and approved to submit the manuscript and there is no conflict of interest.

\section{REFERENCES}

1. Güemes M, Rahman SA, Hussain K. What is a normal blood glucose? Arch Dis Child 2016; 101: 569-574.

2. Beardsall K, Vanhaesebrouck S, Ogilvy-Stuart AL, et al. Prevalence and determinants of hyperglycemia in very low birth weight infants: cohort analyses of the NIRTURE study. J Pediatr 2010; 157: 715-719.e1-e3.

3. Kao LS, Morris BH, Lally KP, Stewart CD, Huseby $\mathrm{V}$, Kennedy KA. Hyperglycemia and morbidity and mortality in extremely low birth weight infants. J Perinatol 2006; 26: 730-736.

4. Hays SP, Smith EO, Sunehag AL. Hyperglycemia is a risk factor for early death and morbidity in extremely low birth-weight infants. Pediatrics 2006; 118: 1811-1818.
5. van der Lugt NM, Smits-Wintjens VEHJ, van Zwieten PHT, Walther FJ. Short and long term outcome of neonatal hyperglycemia in very preterm infants: a retrospective follow-up study. BMC Pediatr 2010; 10: 52.

6. Sabzehei MK, Afjeh SA, Shakiba M, Alizadeh P, Shamshiri AR, Esmaili F. Hyperglycemia in VLBW infants; incidence, risk factors and outcome. Arch Iran Med 2014; 17: 429-434.

7. Mitanchez-Mokhtari D, Lahlou N, Kieffer F, Magny JF, Roger M, Voyer M. Both relative insulin resistance and defective islet beta-cell processing of proinsulin are responsible for transient hyperglycemia in extremely preterm infants. Pediatrics 2004; 113(3 Pt 1): $537-541$.

8. Hey E. Hyperglycaemia and the very preterm baby. Semin Fetal Neonatal Med 2005; 10: 377-387.

9. Manzoni P, Castagnola E, Mostert M, Sala U, Galletto $\mathrm{P}$, Gomirato G. Hyperglycaemia as a possible marker of invasive fungal infection in preterm neonates. Acta Paediatr 2006; 95: 486-493.

10. Heimann K, Peschgens T, Kwiecien R, Stanzel S, Hoernchen H, Merz U. Are recurrent hyperglycemic episodes and median blood glucose level a prognostic factor for increased morbidity and mortality in premature infants $\leq 1500$ gr? J Perinat Med 2007; 35: 245-248.

11. Hall NJ, Peters M, Eaton S, Pierro A. Hyperglycemia is associated with increased morbidity and mortality rates in neonates with necrotizing enterocolitis. J Pediatr Surg 2004; 39: 898-901.

12. Ertl T, Gyarmati J, Gaal V, Szabo I. Relationship between hyperglycemia and retinopathy of prematurity in very low birth weight infants. Biol Neonate 2006; 89: 56-59.

13. Chavez-Valdez R, McGowan J, Cannon E, Lehmann CU. Contribution of early glycemic status in the development of severe retinopathy of prematurity in a cohort of ELBW infants. J Perinatol 2011; 31: 749756.

14. Mohsen L, Abou-Alam M, El-Dib M, Labib M, Elsada M, Aly H. A prospective study on hyperglycemia and retinopathy of prematurity. J Perinatol 2014; 34 : 453-457.

15. Mohamed S, Murray JC, Dagle JM, Colaizy T. Hyperglycemia as a risk factor for the development of retinopathy of prematurity. BMC Pediatr 2013; 13: 78 .

16. Aly H, Hammad TA, Essers J, Wung JT. Is mechanical ventilation associated with intraventricular hemorrhage in preterm infants? Brain Dev 2012; 34: 201-205. 
17. Knezevic S, Stojanovic N, Oros A, Savić D, Simović A, Knezevic J. Analysis of risk factors in the development of retinopathy of prematurity. Srp Arh Celok Lek 2011; 139: 433-438.

18. Şimşek DG, Ecevit A, Hatipoğlu N, et al. Neonatal hyperglycemia, which threshold value, diagnostic approach and treatment?: Turkish Neonatal and Pediatric Endocrinology and Diabetes Societies consensus report. Turk Pediatri Ars 2018; 53(Suppl 1): S234-S238.

19. Decaro MH, Vain NE. Hyperglycemia in preterm neonate: what to know, what to do. Early Hum Dev 2011; 87(Suppl 1): S19-S22.

20. Kairamkonda V, Khashu M. Controversies in the management of hyperglycemia in the ELBW infant. Indian Pediatr 2008; 45: 29-38.

21. Zamir I, Tornevi A, Abrahamsson T, et al. Hyperglycemia in extremely preterm infants-insulin treatment, mortality and nutrient intakes. J Pediatr 2018; 200: 104-110.e1.
22. Alexandrou G, Skiöld B, Karlén J, et al. Early hyperglycemia is a risk factor for death and white matter reduction in preterm infants. Pediatrics 2010; 125: e584-e591.

23. Rozance PJ, Hay WW. Neonatal hyperglycemia. NeoReviews 2010; 11: e632-e639.

24. Bottino M, Cowett RM, Sinclair JC. Interventions for treatment of neonatal hyperglycemia in very low birth weight infants. Cochrane Database Syst Rev 2011; 5: CD007453.

25. Beardsall K, Vanhaesebrouck S, Ogilvy-Stuart AL, et al. Early insulin therapy in very-low-birth-weight infants. N Engl J Med 2008; 359: 1873-1884.

26. Alsweiler JM, Harding JE, Bloomfield FH. Tight glycemic control with insulin in hyperglycemic preterm babies: a randomized controlled trial. Pediatrics 2012; 129: 639-647. 